\title{
Neurological disease and behavioral changes in the human being
}

\author{
Ildefonso Rodríguez-Leyva* \\ Department of Neurology, Faculty of Medicine, Hospital Central Dr. Ignacio Morones Prieto, Universidad Autónoma de San Luis Potosí, SLP, Mexico
}

It is well known that the prominent expression of the work of our brain is behavior, understood as the combination of a structure that expresses a function that is the result of the acquisition of learning overtime of experiences and purchase of skills.

Human behavior is intriguing because each individual expresses it differently, as is the facial expression or the fingerprint.

Behavior is the result of a history written overtime in our genes, a cortical mat growing to fold and forming grooves to be contained in a firm and immovable structure that is the skull.

It is capable of perceiving different stimuli in areas specifically assigned to it. Moreover, it can generate specific responses that originate in phrenologically selected areas but interact in an incredible way to connect with the primitive systems that we maintain in the brain stem and jointly explain genius and the impulsivity that explains a horrible decision unreasoned response.

The human being who achieves a balance in his life is the one who is productive for himself, his family, and society. Possibly happy is the one who manages to passionately love his family and work, combining in everyday life the ability to value what he has and enjoys it. If envy comes, it should be only to force us to surpass ourselves.

However, we live in a society where each individual has his ideas and value judgments. Some understand that self-improvement, justice, honesty, and equity are necessary and desirable values in a society that can continue to improve. However, unfortunately, some see themselves as superior beings who can dominate, manipulate, influence, or even take the lives of others.

Social interaction is already complex due to the characteristics of each individual. Their genetic program, their life experiences, their level of education, their purchasing power make the behavior of human beings a complex expression to evaluate for psychologists, psychiatrists, neurosurgeons, or neurologists, even considering only the biological aspect. This problem is not only for us as physicians; we can either mention philosophers, sociologists, and even politicians.

We have all lived the experience as physicians of a patient with a degenerative disease who went, from being demure, to becoming a verbose, cursing, inopportune, uninhibited, hypersexual, sometimes funny, but at other times extremely reckless individual.

We have also witnessed the false but credible stories for the family of "your brother stole from me, hid from me, took away, took the money you gave me." And that behavior provokes disastrous intrafamily conflicts because the family was not yet aware of the neurodegenerative problem that their relative was beginning to show.

The clingy, dependent, manipulative, absorbing, advantageous behavior that the patient with epilepsy can take; the negligence, the ignorance left-right, the agnosia for faces that can provoke a stroke.
Available online: 07-07-2021

Rev Mex Neuroci. 2021;22(4):132-133 www.revmexneurociencia.com (http://creativecommons.org/licenses/by-nc-nd/4.0/). 
We have also seen the lack of vital impulse, the onset of movement, loss of spontaneity, and affective flattening that can be seen in a bifrontal lesion.

All of this make the analysis of behavior and the determination of normality or abnormality very complex.

We all may have a certain degree of mental illness. And it indeed does no one any harm to have a behavioral evaluation because whether we like it or not, we all must get sick with something just as we will die for some reason.

Those of us who assess brain disease should constantly strive to maintain proper behavior in a complicated society and be aware of the risk we will always face of suffering from brain disease.

"In our case, in order to give we will always have to have health."

In the meantime, if we can enjoy reading and continue to learn about our brains and the brains of others, let us love with passion not only our family but also the fantastic job we have been given in society as health-care providers. Let us perform the miracles that we are called to serve, thanks to the knowledge and skills that we have acquired throughout our training, and let us infect others to follow this exciting path of neurosciences. 